\title{
Draft Genome Sequence of Brevibacillus borstelensis cifa_chp40, a Thermophilic Strain Having Biotechnological Importance
}

\author{
Swetaleena Tripathy, Soumesh Kumar Padhi, Rinil Sen, Ushajyoti Maji, Mrinal Samanta, Sriprakash \\ Mohanty and Nikhil Kumar Maiti ${ }^{\bowtie}$
}

Environmental Microbiology Unit, Division of Fish Health Management, Central Institute of Freshwater Aquaculture, Kausalyaganga, Bhubaneswar-751002, Odisha, India.

\section{$\square$ Corresponding author: Dr. N K Maiti, E-mail: maitink@yahoo.co.in Phone: 91-674-2465421 Fax: 91-674-2465407.}

() Ivyspring International Publisher. Reproduction is permitted for personal, noncommercial use, provided that the article is in whole, unmodified, and properly cited. See http://ivyspring.com/terms for terms and conditions.

Published: 2016.02.15

\begin{abstract}
Brevibacillus borstelensis cifa_chp40 is a thermophilic, strictly aerobic gram positive motile bacteria isolated from the alkaline hot water spring located in the Eastern Ghats zone of India. It could grow in a wide range of temperature and degrade low-density polythene at $37^{\circ} \mathrm{C}$. The strain cifa_chp40 produces essential enzymes like protease, lipase, esterase and amidase at $50^{\circ} \mathrm{C}$. Here, we report the draft genome sequence of $B$. borstelensis cifa_chp 40 which will provide further insight into the metabolic capabilities, function and evolution of this important organism.
\end{abstract}

Key words: Brevibacillus borstelensis, Hot water spring, Enzyme production, Draft genome.

\section{Introduction}

Brevibacillus borstelensis sp. nov., nom. rev. belonging to family Paenibacillaceae has been classified into a distinct group based on the phenotypic characteristics, DNA base composition, re-association analyses and results of cellular fatty acid and isoprenoid quinone composition analyses (1). B. borstelensis is closely related with Bacillus centrosporus (2) and $B a$ cillus choshinensis (3). B. borstelensis has been described as strictly aerobic, gram-positive, spore forming, rod-shaped, motile bacteria. B. borstelensis isolated from different ecosystems have shown potential application in polythene degradation (4). B. borstelensis have been also reported to produce industrially important enzymes like amidase (5), amylase (6) and protease (7).

Brevibacillus borstelensis cifa_chp40 was isolated from Attri hot water spring $\left(20^{\circ} 09^{\prime} \mathrm{N} 85^{\circ} 18^{\prime} \mathrm{E}\right)$ of Odisha, India. The bacteria can grow in a wide range of temperature from $20^{\circ} \mathrm{C}$ to $65^{\circ} \mathrm{C}$ and is able to degrade low-density polythene at $37^{\circ} \mathrm{C}$. The strain produces industrially important enzymes like amidase, lipase, protease and esterase at an optimum growth temperature of $50^{\circ} \mathrm{C}$. Production of enzymes by thermophilic $B$. borstelensis at high temperatures has been previously reported $(5,8-10)$. For in depth genomic study and potential applications of the bacteria, B. borstelensis cifa_chp40 was subjected to whole genome sequencing on Illumina MiSeq platform (Illumina Inc., CA) using $2 \times 250$ bp sequencing kit. Genomic DNA was extracted from the bacterial culture grown in Nutrient broth medium at $50^{\circ} \mathrm{C}$. Following DNA fragmentation and adapter ligation, the paired-end sequencing library was prepared using Illumina TruSeq DNA library preparation kit. After quality filtration (mean quality score $\geq 25$ ) and adapter trimming using Trimmomatic software, high quality data was assembled using CLC genomics workbench based on default set of parameters (Mismatch $\operatorname{cost}=2$, 
Insertion cost $=3$, Deletion cost $=3$, Length fraction $=$ 0.5 and Similarity fraction $=0.8$ ) to obtain the scaffolds. The coding sequences (CDS) were predicted from the scaffolds using 'Prodigal' software, which is a microbial gene-finding program (11). Ribosomal and transfer RNAs were identified by aligning the scaffolds to Rfam database (12). The predicted CDS were annotated by comparison with non-redundant protein database of NCBI using BLASTX (13). Functional annotation of the sequences was performed using Gene Ontology (GO) terms with Blast2GO V2.8.0 software. Transposable elements were identified by Transposon PSI program (http://transposonpsi.sourceforge.net). Simple sequence repeats were determined using 'MISA', that allows the identification and localization of different microsatellites.

A total of $37,456,348$ high quality paired-end reads with $347 X$ coverage (mean read length $147 \mathrm{bp}$ ) were obtained. The total length of the genome was found to be 5,196,578 bp assembled into 38 scaffolds with 14 scaffolds having $>20,000 \mathrm{bp}$ and 6 scaffolds having $>30,000 \mathrm{bp}$ length. The $\mathrm{G}+\mathrm{C}$ content was $51.90 \%$. The draft genome of B. borstelensis cifa_chp40 harbored 5103 genes that encoded 4831 protein-coding genes including 113 tRNA and 3 rRNA genes (Table 1). Based on GO annotation, maximum CDS were categorized under molecular functions (615) followed by biological processes (468) and cel- lular components (159). Greater number of sequences was classified under the GO categories viz., catalytic activity, metabolic process, cellular process, binding, cell, cell part, localization and macromolecular complex (Figure 1). Besides, three transposable elements (ISC1316, LINE and ISC1316) and four simple sequence repeats were identified. The genome sequence of $B$. borstelensis cifa_chp40 encoded chaperone proteins and essential enzymes involved in large scale processes and required for production of different biomolecules. These enzymes include metalloprotease, serine peptidase, phospholipase, metallophosphoesterase, penicillin amidase and amidohydrolase and are involved in various biosynthesis and metabolic processes. The draft genome features of $B$. borstelensis cifa_chp40 indicate the biotechnological implication of the thermophilic bacteria in producing enzymes of industrial significance.

Table 1. Genome features of Brevibacillus borstelensis cifa_chp40.

\begin{tabular}{ll}
\hline Features & Values \\
\hline Genome size & $5,196,578 \mathrm{bp}$ \\
Total number of scaffolds & 38 \\
G+C content & $51.90 \%$ \\
Total number of genes & 5103 \\
Total number of protein-coding genes & 4831 \\
Plasmid & 0 \\
tRNA genes & 113 \\
rRNA genes & 3 \\
\hline
\end{tabular}

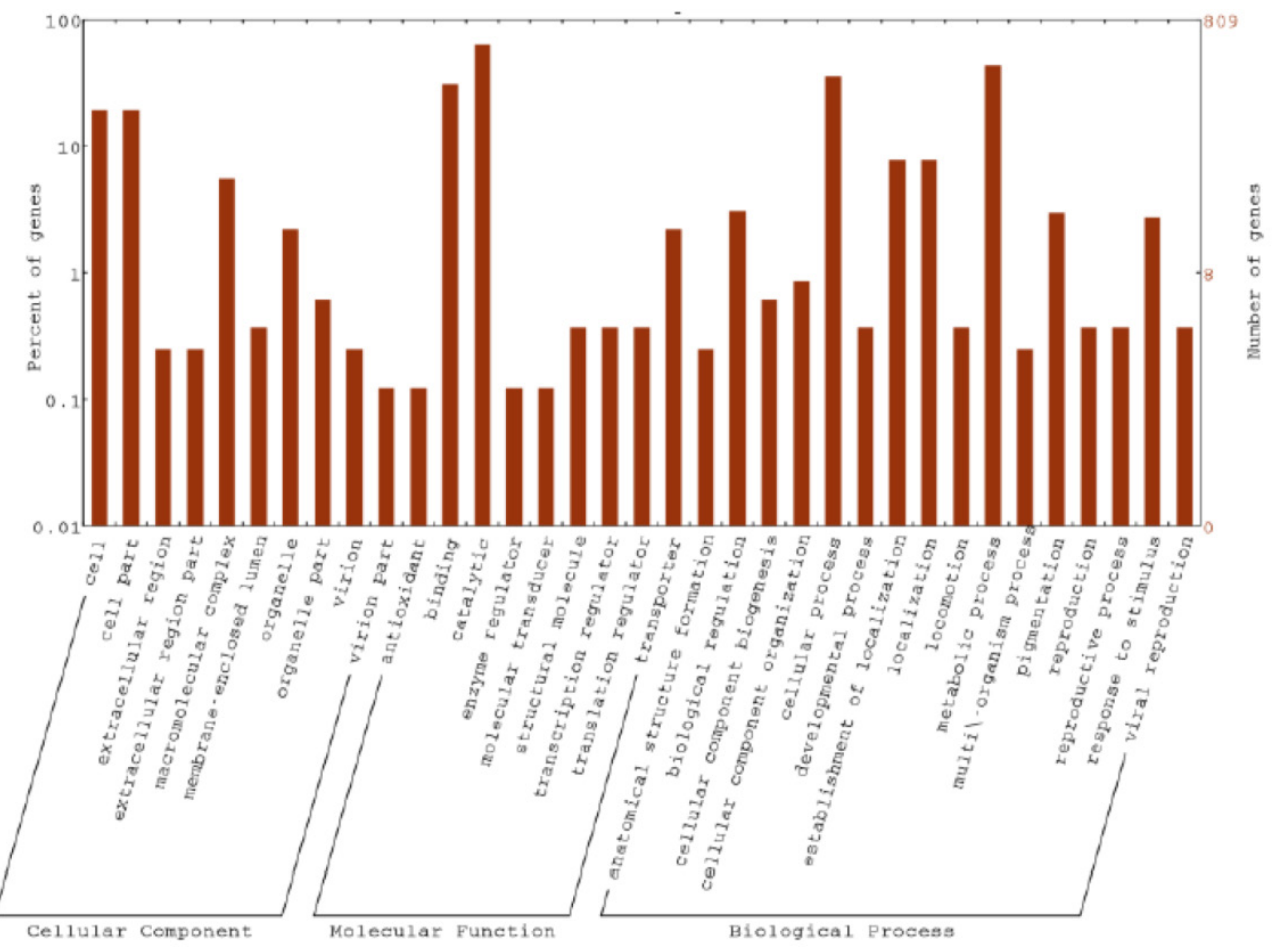

Figure 1. Classification of protein-coding genes based on gene ontology into three main categories: biological processes, molecular functions and cellular components. The $y$-axis on the right indicates the number of genes in a category. The $y$-axis on the left indicates percentage of a specific category of genes in the main category. 


\section{Nucleotide sequence accession number}

The draft genome sequence of Brevibacillus borstelensis cifa_chp40 was deposited in the Genbank database under the accession number JPRB00000000.

\section{Acknowledgements}

This work was supported by National Agricultural Innovation Project under Indian Council of Agriculture Research, India. Authors are also thankful to the Director, Central institute of Freshwater Aquaculture for providing necessary facilities to carry out this work.

\section{Competing Interests}

The authors have declared that no competing interest exists.

\section{References}

1. Shida O, Takagi H, Kadowaki K, Udaka S, Nakamura LK, Komagata K. Proposal of Bacillus reuszeri sp. nov., Bacillus formosus sp. nov., nom rev., and Bacillus borstelensis sp. nov., nom. rev. Int J Syst Bacteriol. 1995; 45: 93-100.

2. Nakamura LK. DNA relatedness of Bacillus brevis Migula 1900 strains and proposal of Bacillus agri sp. nov., nom. rev., and Bacillus centrosporus sp. nov., nom. rev. Int J Syst Bacteriol. 1993; 43: 20-25.

3. Takagi H, Shida O, Kadowaki K, Komagata K, Udaka S. Characterization of Bacillus brevis, with description of Bacillus migulanus sp. nov., Bacillus choshinensis sp. nov., Bacillus parabrevis, sp. nov., and Bacillus galuctophilus sp. Int J Syst Bacteriol. 1993; 43: 221-231.

4. Hadad D, Geresh S, Sivan A. Biodegradation of polyethylene by the thermophilic bacterium Brevibacillus borstelensis. J App Microbiol. 2005; 98: 1093-1100.

5. Baek DH, Song JJ, Lee SG, Kwon SJ, Asano Y, Sung MH. New thermostable D-methionine amidase from Brevibacillus borstelensis BCS-1 and its application for D-phenylalanine production. Enz Microbial Tech. 2003; 32: 131-139.

6. Suribabu K, Govardhan TL, Hemalatha KPJ. Application of partially purified -amylase produced by Brevibacillus borostelensis R1 on sewage and effluents of Industries. Int J Curr Microbiol App Sci. 2014; 3(7): 691-697.

7. Rai SK, Mukherjee AK. Optimization of production of an oxidant and detergent-stable alkaline $\beta$-keratinase from Brevibacillus sp. strain AS-S10-II: Application of enzyme in laundry detergent formulations and in leather industry. Biochemical Eng J. 2011; 54: 47-56.

8. Bisht, SPS, Panda, AK. Isolation and identification of new lipolytic thermophilic bacteria from an Indian hot spring. Int J Pharma and Bio Sci. 2011; 2(2): 229-235.

9. Baek DH, Song JJ, Kwon SJ, Park C, Jung CM, Sung MH. Characteristics of a new enantioselective thermostable dipeptidase from Brevibacillus borstelensis BCS-1 and its application to synthesis of a D-amino-acid-containing dipeptide. App Env Microbiol. 2004; 70(3): 1570-1575.

10. Kwon SJ, Baek DH, Lee SG, Sung MH. Simple and rapid screening method for microbial D-stereospecific peptidase and esterase. Biotechnol Techniques 1999; 13: 653-655.

11. Hyatt D, Chen GL, LoCascio PF, Land ML, Larimer FW, Hauser LJ Prodigal: prokaryotic gene recognition and translation initiation site identification. BMC Bioinformat. 2010; 11: 119.

12. Jones SG, Bateman A, Marshall M, Khanna A, Eddy SR. Rfam: an RNA family database. Nucleic Acids Res. 2003; 31(1): 439-441.

13. Altschul SF, Madden TL, Schaffer AA, Zhang J, Zhang Z, Miller W, Lipman DJ. Gapped BLAST and PSI-BLAST: a new generation of protein database search programs. Nucleic Acids Res. 1997; 25: 3389-3402. 